\title{
THE PITFALL OF RELYING ON A SPHYGMOMANOMETER DURING A HYPERTENSIVE CRISIS
}

\author{
TOH LEONG TAN ${ }^{1}$, CHUAN HUN DING ${ }^{2 *}$
}

${ }^{1}$ Department of Emergency Medicine, Faculty of Medicine, Universiti Kebangsaan Malaysia, Kuala Lumpur, Malaysia. ${ }^{2}$ Department of Medical Microbiology and Immunology, Faculty of Medicine, Universiti Kebangsaan Malaysia, Kuala Lumpur, Malaysia. Email: dingch@ppukm.ukm.edu.my

Received: 15 October 2018, Revised and Accepted: 19 November 2018

\begin{abstract}
Hypertensive crises can be life-threatening if undiagnosed due to the risk of acute target organ damage. This is a case of a middle-aged woman with poorly controlled hypertension who presented with a 3-day history of dyspnea, orthopnea, and cough productive of frothy sputum. Repeated attempts to measure her blood pressure (BP) using both a mercury and an electronic sphygmomanometer were unsuccessful. However, when an arterial catheterization of the right radial artery was performed, her mean BP was 358/151 mm Hg. A chest X-ray revealed cardiomegaly with plethoric lung fields. Following a diagnosis of hypertensive emergency with acute pulmonary edema, a glyceryl trinitrate infusion at a dose of 20 mg/min was commenced and titrated in an escalating manner. She was also given a single dose of intravenous frusemide 40 mg. Her BP was successfully reduced by $25 \%$ within $3 \mathrm{~h}$ of presentation.
\end{abstract}

Keywords: Arterial catheter, Hypertensive crisis, Hypertensive emergency, Sphygmomanometer.

(C) 2019 The Authors. Published by Innovare Academic Sciences Pvt Ltd. This is an open access article under the CC BY license (http://creativecommons. org/licenses/by/4. 0/) DOI: http://dx.doi.org/10.22159/ajpcr.2019.v12i1.30272

\section{INTRODUCTION}

In Malaysia, the prevalence of hypertension in 2011 was $32.7 \%$ in individuals aged at least 18 years and $43.5 \%$ in individuals aged 30 years or older [1]. Therefore, it is not uncommon to see patients with hypertensive crises in the emergency departments (EDs) in this country. Hypertensive crises can be broadly divided into hypertensive emergencies and hypertensive urgencies. A hypertensive emergency is defined as a blood pressure (BP) reading of at least 180/120 mm Hg with imminent or progressive target organ dysfunction, while a hypertensive urgency is defined as a BP of at least $180 / 120 \mathrm{~mm} \mathrm{Hg}$ without imminent or progressive target organ dysfunction [2]. Managing hypertension in the ED can be challenging. Many trials have attempted to address the issue of managing hypertensive emergencies [3,4]. However, the wide scope of the term "hypertensive emergency" and variabilities in the criteria used by various authors for diagnosing the disorder has made clinical trial comparisons difficult. This is a case of a patient with an extremely high BP (systolic BP in excess of $350 \mathrm{~mm} \mathrm{Hg}$ ) and the pitfall of relying on a sphygmomanometer during a hypertensive crisis.

\section{CASE REPORT}

A 49-year-old Malay woman with a background history of poorly controlled hypertension and hyperlipidemia presented to the ED of our medical center with a chief complaint of severe shortness of breath for 3 days. Her other complaints were chest pain, productive cough with frothy sputum, orthopnea, and paroxysmal nocturnal dyspnea for the past 3 days. She claimed that she was not compliant with the antihypertensive and antihyperlipidemic medications. She was previously taking oral prazosin $1 \mathrm{mg} 3$ times daily for hypertension. On examination, she was sitting in the tripod position and gasping for air. She was otherwise alert, conscious and was able to converse coherently. Her Glasgow Coma Scale Score was 15. Multiple attempts were made to measure her BP using an electronic as well as a mercury sphygmomanometer, but no reading could be recorded. She had a heart rate of 129 beats/min, a body temperature of $37.4^{\circ} \mathrm{C}$ and her oxygen saturation was $95 \%$ on room air. She had an elevated jugular venous pressure and a displaced apex beat. Auscultation of her lungs revealed fine crepitation and scattered rhonchi up to the apex. She also had pedal edema up to both thighs.
The patient was immediately put on continuous positive airway pressure with a positive end-expiratory pressure of $7 \mathrm{~cm} \mathrm{H}_{2} \mathrm{O}$ and a fraction of inspired oxygen of 1.0. An arterial catheterization of her right radial artery was performed to enable direct BP measurements. Following this, her mean BP was found to be $358 / 151 \mathrm{~mm} \mathrm{Hg}$. Her chest X-ray showed cardiomegaly with radiological evidence of pulmonary edema (Fig. 1). An electrocardiogram revealed tachycardia and left ventricular hypertrophy. The patient was diagnosed to have a hypertensive emergency with acute pulmonary edema. An intravenous infusion of glyceryl trinitrate at a dose of $20 \mathrm{mg} / \mathrm{min}$ was commenced and titrated in an escalating manner. She was also given a single dose of intravenous frusemide $40 \mathrm{mg}$. A continuous bladder drainage catheter was inserted for urine output monitoring. Her BP was successfully reduced by $25 \%$ within $3 \mathrm{~h}$ of her presentation to the ED.

The patient's mean BP reading on the day of discharge was 156/65 mm Hg. As presented in Table 1, the BP on discharge was significantly lower compared to the BP on admission. She was counseled by the ward pharmacist on the importance of drug compliance and allowed home with three oral anti-hypertensive medications.

\section{DISCUSSION}

This article highlights some pertinent issues regarding the methods of BP measurement and the importance of referring to current clinical practice guidelines when managing a patient with extremely high BP. Specifically, this case demonstrates the limitation of relying on indirect BP measurement methods in a medical emergency. Both the automated (i.e., electronic) and manual sphygmomanometers had failed to record our patient's BP. The reason for the inherent failure of both devices is the simple fact that they are only able to record BPs of up to $300 \mathrm{~mm} \mathrm{Hg}$. Furthermore, using an indirect method of BP measurement to quantify an extremely high BP will also inflict significant discomfort or even pain at the cuff placement site, hence making accurate BP measurements progressively impossible. Therefore, any indirect measurement of extreme high BPs may not be reliable.

For this hypertensive crisis case, we had to place a catheter in a peripheral artery with a $\mathrm{BP}$ transducer to directly measure the 


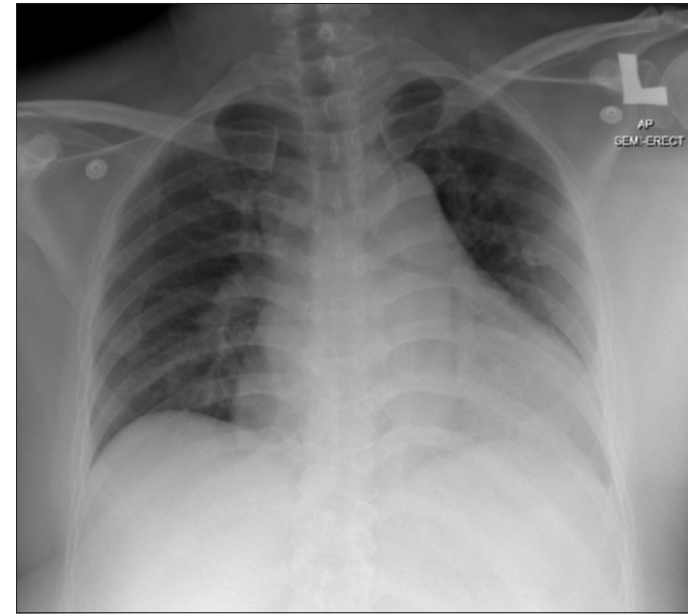

Fig. 1: Portable chest X-ray showing cardiomegaly and bilateral plethoric lung fields suggestive of acute pulmonary edema

Table 1: Mean BP on admission and on discharge

\begin{tabular}{llll}
\hline BP component & On admission & On discharge & Pvalue \\
\hline SBP $(\mathrm{mm} \mathrm{Hg})$, mean \pm SD & $358 \pm 11$ & $156 \pm 13$ & $0.005^{*}$ \\
DBP (mm Hg), mean \pm SD & $151 \pm 2$ & $65 \pm 7$ & $0.033^{*}$ \\
\hline
\end{tabular}

*Statistically significant with paired t-test. SBP: Systolic blood pressure,

DBP: Diastolic blood pressure, SD: Standard deviation, BP: Blood pressure

BP. This also enabled us to carry out beat-to-beat monitoring of the BP, especially when close monitoring of our patient's BP was also desirable. Direct BP measurement through an intraarterial catheter has been proven to be both accurate and reliable [5]. It has been recommended that for patients with very severe clinical manifestations and/or highly labile BPs, performing intra-arterial BP monitoring may be prudent [6]. Our patient also required admission to the high dependency ward, where we aimed for a $25 \%$ reduction in the systolic BP over the first 1-3 h, in accordance to recommended clinical practice guidelines [1,2]. The patient tolerated the intervention well without any apparent complications until the targeted BP was achieved within $3 \mathrm{~h}$.

Once the initial mean arterial BP reduction of $25 \%$ has been achieved, the BP should be reduced further to $160 / 100-110 \mathrm{~mm} \mathrm{Hg}$ within the next 2-6 $\mathrm{h}$ [2]. Excessive falls in BP may precipitate renal, cerebral, or coronary ischemia and should be avoided. According to the findings of major randomized controlled studies, high-dose intravenous nitrate administered in combination with a low-dose diuretic can effectively treat acute pulmonary edema [7]. A similar treatment was given to our patient as well and she showed clinical improvement within the first $3 \mathrm{~h}$ of her presentation to the ED. The importance of providing patient education or counseling to hypertensive patients before their discharge from the hospital must be emphasized because it has been shown that compliance to drug therapy can be improved significantly, particularly when mediated by pharmacists [8-10].

\section{CONCLUSION}

The effective measurement of extremely high BPs is challenging. It is important to note that limitations exist with both automated and manual sphygmomanometers in measuring extremely high BPs. Therefore, direct BP measurement through an intra-arterial catheter may be prudent in certain cases.

\section{ACKNOWLEDGMENT}

We would like to thank the Dean of the Faculty of Medicine, Universiti Kebangsaan Malaysia, for her motivation and permission to publish this article.

\section{AUTHORS' CONTRIBUTIONS}

Study conception and design: Toh Leong Tan. Data collection and analysis: Toh Leong Tan. Drafting of the article and revising it critically for important intellectual content: Chuan Hun Ding and Toh Leong Tan. Final approval of the version to be submitted: Chuan Hun Ding and Toh Leong Tan.

\section{CONFLICTS OF INTEREST}

Both authors declare that they have no conflicts of interest.

\section{REFERENCES}

1. Ministry of Health Malaysia. Clinical Practice Guidelines: Management of Hypertension. $4^{\text {th }}$ ed. Putrajaya: Ministry of Health; 2013.

2. Chobanian AV, Bakris GL, Black HR, Cushman WC, Green LA, Izzo JL Jr, et al. The seventh report of the joint national committee on prevention, detection, evaluation, and treatment of high blood pressure: The JNC 7 report. JAMA 2003;289:2560-72.

3. Salkic S, Brkic S, Batic-Mujanovic O, Ljuca F, Karabasic A, Mustafic S, et al. Emergency room treatment of hypertensive crises. Med Arch 2015;69:302-6.

4. Rock W, Zbidat K, Schwartz N, Elias M, Minuhin I, Shapira R, et al. Pattern of blood pressure response in patients with severe asymptomatic hypertension treated in the emergency department. J Clin Hypertens (Greenwich) 2016;18:796-800.

5. Pickering TG, Hall JE, Appel LJ, Falkner BE, Graves J, Hill MN, et al. Recommendations for blood pressure measurement in humans and experimental animals: Part 1: Blood pressure measurement in humans: A statement for professionals from the subcommittee of professional and public education of the american heart association council on high blood pressure research. Circulation 2005;111:697-716.

6. Flanigan JS, Vitberg D. Hypertensive emergency and severe hypertension: What to treat, who to treat, and how to treat. Med Clin North Am 2006;90:439-51.

7. Cotter G, Metzkor E, Kaluski E, Faigenberg Z, Miller R, Simovitz A, et al. Randomised trial of high-dose isosorbide dinitrate plus low-dose furosemide versus high-dose furosemide plus low-dose isosorbide dinitrate in severe pulmonary oedema. Lancet 1998;351:389-93.

8. Thomas JA, Snigdha KS, Karanath PM, Swaroop AM. Impact of patient counselling on knowledge, attitude, and practice of hypertensive patients in a tertiary care hospital. Int J Pharm Pharm Sci 2017;9:122-5.

9. Nasution A, Khairunnisa, Tanjung HR. Impacts of counseling on adherence to prescribed medications and blood pressure of hypertensive patients in four Indonesian primary health centers. Int J Pharm Pharm Sci 2015;7:114-7.

10. Mah HC, Muthupalaniappen L, Chong WW. Perceived involvement and preferences in shared decision-making among patients with hypertension. Fam Pract 2016;33:296-301. 